\title{
Comparison of Jet Pump Numerical Calculation Results in ANSYS and Openfoam CFD Packages
}

\author{
A. S. Klyuyev ${ }^{*}$, Y. I. Chernyshev ${ }^{1}$, E. A. Ivanov ${ }^{1}$ and I. O. Borshchev ${ }^{1}$ \\ ${ }^{1}$ Peter the Great St.Petersburg Polytechnic University, St.Petersburg, Russia
}

\begin{abstract}
Currently, among the most popular computational fluid dynamics software packages are commercial CFD packages - ANSYS CFX, ANSYS Fluent, STAR-CCM+ and several others. In contrast to the abovementioned commercial CFD packages, there is an OpenFOAM, a noncommercial, freely distributed, integrated platform for numerical modeling of solid-state mechanics tasks (including CFD tasks), and it is becoming more and more popular. In addition to being a non-commercial package, OpenFOAM also has open-source code, which allows users to write their own algorithms for solving highly specialized tasks. A comparison of ANSYS and OpenFOAM in the application to CFD problems of incompressible turbulent flow in this article is given by the example of jet pump calculation, which was tested in the Laboratory of Hydraulic Machinery of Peter the Great St.Petersburg Polytechnic University.
\end{abstract}

\section{Introduction}

Jet pump is a hydraulic machine, where mixing of the flows is followed by the transportation of the finished product to the consumer. At that, the ratio of the flow rates of working and injected flows in the jet pump is determined by the design (geometric dimensions of the flow part) and the operating (heads in suction and discharge control sections of the pump) parameters. Flow rates ratio will remain constant in case design and operating parameters are unchanged. The working process of the device is accompanied by energy exchange and mutual mixing of flows due to turbulent flow regime and subsequent alignment of velocity and pressure profiles. This results in the formation of mixture, containing required composition and energy, sufficient for subsequent transfer to the consumer.

\section{Experimental studies}

Experimental studies of the jet pump were conducted in Hydraulic Engineering Laboratory, the purpose of the studies was to obtain detailed description of the jet pump industrial prototype operation, as well as research related to its efficiency improving.

The installation diagram is shown in figure 1. The jet pump was installed on the pipeline, the working fluid supply was provided using 2 pumps connected to each other in series, so

\footnotetext{
*Corresponding author: arsentiyklyuyev@gmail.com
} 
that the maximum head of the working fluid during the tests comprised $100 \mathrm{~m}$. Water was sucked through the suction pipe from the Laboratory pool and together with the working fluid was fed to a tray with triangular notch, measuring the total flow through the system.

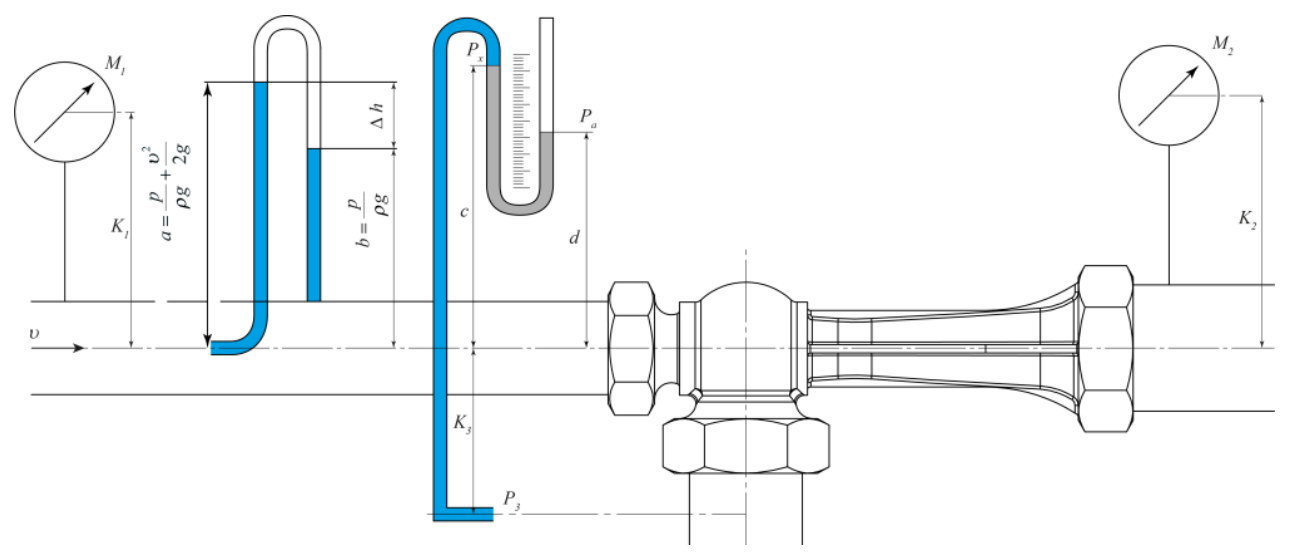

Fig. 1. Experimental set-up and instruments arrangement diagram.

During the jet pump testing process some of the parameters characterizing its performance were measured directly, and some were determined by calculation.

Directly measured parameters were:

- Pressure of liquid in the rising pipe $P_{1} /$ Pressure gauge № $1 / M_{1}$;

- Pressure of liquid in the discharge pipe $P_{2} /$ Pressure gauge № $2 / M_{2}$;

- Average velocity in the rising pipe $v_{1} /$ Pitot tube / dimensions " $a$ " and " $b "$;

- Total flow through $Q_{2}$ ejector / through the notch;

- Pressure in the suction pipe at the entrance to $P_{3}$ ejector / mercury piezometer / dimensions " $c$ " and " $d$ ";

- Rising pipe cross section $/ f_{1}$;

- Discharge pipe cross section $/ f_{2}$;

- Suction pipe cross section $/ f_{3}$;

- The distance from the pipe axis to the center of the dials of pressure gauges № 1 and № 2 , to the zero point of the mercury piezometer $/ K 1, K 2$, and $K 3$, respectively.

Calculated parameters were:

- Flow in the discharge pipe $Q_{1} /$ using average velocity $v_{1}$ and area $f_{1}$;

- Flow in the suction pipe $Q_{2} /$ as difference $Q_{2}-Q_{1}$;

- Velocity in the suction pipe $v_{3} /$ using flow rate $Q_{3}$ and cross section $f_{3}$;

- Velocity in the discharge pipe $v_{2} /$ using flow rate $Q_{2}$ and cross section $f_{2}$;

- Total suction height $h_{3}$;

- Efficiency coefficient $\eta$.

Height related position of instruments (pressure gauges, piezometers, vacuum meters) was considered using respective increments to their readings:

$\left(P_{1} / \gamma\right)_{\mathrm{g}}=$ reading of the pressure gauge № $1+K_{1}$, where $K_{1}$ is pressure gauge № 1 elevation over the axis of the jet pump in [m], i.e.:

$$
\left(\frac{P_{1}}{\gamma}\right)_{g}=M_{1}+K_{1}
$$


$\left(P_{2} / \gamma\right)_{\mathrm{g}}=$ reading of the pressure gauge № $2+K_{2}$, where $K_{2}$ is pressure gauge № 1 elevation over the axis of the jet pump in $[\mathrm{m}]$, i.e.:

$$
\left(\frac{P_{2}}{\gamma}\right)_{g}=M_{2}+K_{2} ;
$$

$\left(P_{3} / \gamma\right)_{\text {abs }}=$ vacuum gauge reading $+K_{3}$, where $K_{3}$ is vacuum gauge elevation over the axis of the jet pump in $[\mathrm{m}]$, i.e.:

$$
\left(\frac{P_{3}}{\gamma}\right)_{a b s}=W+K_{3}
$$

$\left(P_{3} / \gamma\right)_{\mathrm{vac}}=K_{3}-$ vacuum gauge reading, where $K_{3}$ is vacuum gauge elevation over the axis of the jet pump in $[\mathrm{m}]$, i.e.:

$$
\left(\frac{P_{3}}{\gamma}\right)_{v a c}=K_{3}-W .
$$

In the course of the test the constants $K_{1}, K_{2}$, and $K_{3}$ were equal to: $K_{1}=0.4 \mathrm{~m}$; $K_{2}=0.39 \mathrm{~m} ; K_{3}=0.725 \mathrm{~m}$.

To consider the influence of the pipe elements on Pitot tube readings, the latter was calibrated: the speed was measured with the Pitot tube at different operating head values, and simultaneously by the pipe cross-section and the flow rate measured at the notch. Pitot tube calibration coefficient was determined by comparison of these parameters:

$$
v_{1}=\varphi \sqrt{2 g(a-b)}=Q_{1} / f_{1}
$$

where $Q_{1}$ - flow rate measured at the notch, $f_{1}$ - pipe cross-section.

On the basis of these two conditions:

$$
\varphi=\frac{Q_{1}}{f_{1} \sqrt{2 g(a-b)}} .
$$

According to calibration for 2-inch pipe, it was obtained $\varphi=0.374$, and the speed determined with the Pitot tube:

\begin{tabular}{|c|c|c|c|c|c|c|c|c|c|c|c|c|c|c|}
\hline № & $\begin{array}{l}P_{1} / \gamma \\
(\mathrm{m})\end{array}$ & $\underset{(1 / \mathbf{s})}{Q_{1}}$ & $\begin{array}{c}v_{1} \\
(\mathbf{m} / \mathbf{s})\end{array}$ & $\begin{array}{c}v_{1}{ }^{2} / 2 \mathrm{~g} \\
(\mathrm{~m})\end{array}$ & $\begin{array}{l}P_{2} / \gamma \\
(\mathrm{m})\end{array}$ & $\begin{array}{c}h \\
(\mathrm{~m})\end{array}$ & $\underset{(\mathbf{l} / \mathbf{s})}{Q_{2}}$ & $\begin{array}{c}v_{2} \\
(\mathrm{~m} / \mathrm{s})\end{array}$ & $\begin{array}{c}v_{2}{ }^{2} / 2 \mathrm{~g} \\
(\mathrm{~m})\end{array}$ & $\underset{(\mathbf{l} / \mathbf{s})}{Q_{3}}$ & $\begin{array}{c}v_{3} \\
(\mathrm{~m} / \mathrm{s})\end{array}$ & $\begin{array}{c}v_{3}{ }^{2} / 2 \mathrm{~g} \\
(\mathrm{~m})\end{array}$ & $\begin{array}{c}h_{3} \\
(\mathbf{m})\end{array}$ & $\begin{array}{c}\eta \\
(\%)\end{array}$ \\
\hline 1 & 80.35 & 3.60 & 1.84 & 0.173 & \begin{tabular}{|l|}
14.39 \\
\end{tabular} & 0.121 & 7.22 & 2.29 & 0.267 & 3.62 & 1.150 & \begin{tabular}{|l|}
0.067 \\
\end{tabular} & 2.005 & 25.3 \\
\hline 2 & 70.35 & 3.36 & 1.72 & 0.151 & 12.39 & 0.118 & 6.80 & 2.16 & 0.238 & 3.44 & 1.090 & 0.061 & 1.765 & 25.4 \\
\hline 3 & 60.35 & 3.10 & 1.58 & 0.127 & 10.59 & 0.115 & 6.30 & 2.00 & 0.204 & 3.20 & 1.015 & \begin{tabular}{|l|}
0.053 \\
\end{tabular} & 1.575 & 25.6 \\
\hline 4 & 50.35 & 2.92 & 1.49 & 0.113 & 9.19 & 0.111 & 5.85 & 1.86 & 0.176 & 2.93 & 0.930 & 0.044 & 1.445 & 26.3 \\
\hline 5 & 40.35 & 2.60 & 1.33 & 0.090 & 7.19 & 0.103 & 4.85 & 1.54 & 0.121 & 2.25 & 0.714 & 0.026 & 1.195 & 22.2 \\
\hline
\end{tabular}

$$
v_{1}=0.374 \sqrt{2 g(a-b)}
$$

The results of experimental studies of the investigated jet pump are presented in table 1 .

Table 1. Results of experimental studies. 


\begin{tabular}{|l|l|l|l|l|l|l|l|l|l|l|l|l|l|l|}
\hline 6 & 30.35 & 2.23 & 1.14 & 0.066 & 5.39 & 0.097 & 4.20 & 1.33 & 0.090 & 1.97 & 0.625 & 0.020 & 1.015 & 22.94 \\
\hline 7 & 20.35 & 1.69 & 0.86 & 0.038 & 3.39 & 0.086 & 3.15 & 1.00 & 0.051 & 1.46 & 0.463 & 0.011 & 0.825 & 21.7 \\
\hline
\end{tabular}

\section{Numerical calculation of the jet pump}

Main geometrical parameters of the investigated jet pump: workflow inlet section diameter $-50 \mathrm{~mm}$. injected flow inlet section diameter is $65 \mathrm{~mm}$. flow section diameter at ejector outlet is $65 \mathrm{~mm}$. nozzle diameter is $11 \mathrm{~mm}$. mixing chamber diameter is $22.5 \mathrm{~mm}$.

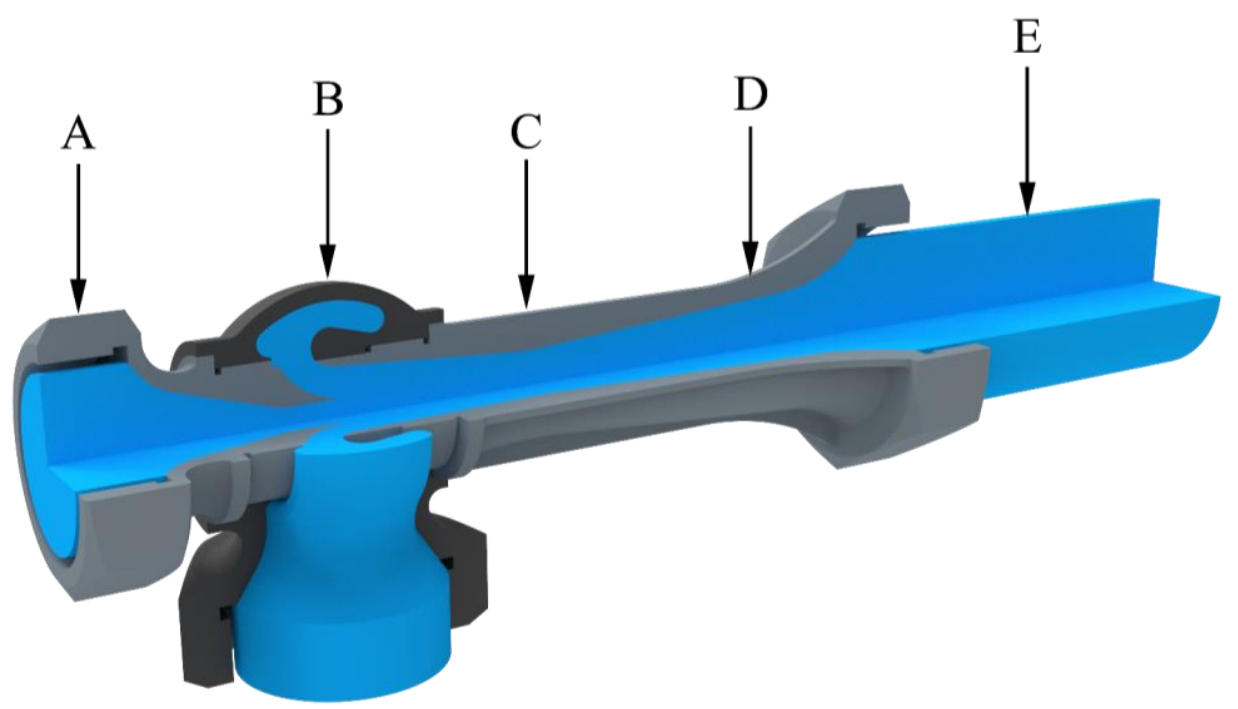

Fig. 2. The main elements of a jet pump: A - motive nozzle; B - suction chamber; $\mathrm{C}$ - mixing chamber; $\mathrm{D}$ - diffuser; $\mathrm{E}$ - calculated liquid domain.

\subsection{Mesh independence studies}

A series of mesh independence calculations were performed using ANSYS software package in order to exclude the influence of the number of computational grid elements on the calculation results. Only the number of elements of unstructured tetrahedral computational region grid of the calculated area of the jet pump flow part was changed in each new calculation; the geometry and the boundary conditions remained the same. Total pressure $P_{3}=81583 \mathrm{~Pa}$ was set at the boundary of passive flow inlet, total pressure $P_{1}=787557 \mathrm{~Pa}$ was set at the active flow inlet, static pressure $P_{2}=140742 \mathrm{~Pa}$ was set at mixed flow outlet. These parameters correspond to point № 1 of the test report on taking the pump performance data (see table 1). The pump support pressure was assumed to be zero.

$\mathrm{k}-\varepsilon$ turbulence model was used in the calculations. Working medium properties were described using Water Liquid model (density $\rho=998.2 \mathrm{~kg} / \mathrm{m}^{3}$; molar mass $\mu=0.018 \mathrm{~kg} / \mathrm{mol})$.

Main criteria for the shape of elements (mesh) are Orthogonal Quality (orthogonality) and Skewness (asymmetry).

It is recommended to use grid models for which the minimum Orthogonal Quality value is $>0.1$ (table 2), or the maximum Skewness value is $<0.95$ (table 3). It is possible to go beyond these limits in cases of relatively simple flows, as well as in areas with insignificant gradients of variables. 
Table 2. Orthogonal Quality mesh quality indicator.

\begin{tabular}{|c|c|c|c|c|c|}
\hline Unacceptable & Poor & Acceptable & Good & Very good & Excellent \\
\hline $0-0.001$ & $0.001-0.10$ & $0.10-0.20$ & $0,20-0,69$ & $0.70-0.95$ & $0.95-1.00$ \\
\hline
\end{tabular}

Table 3. Skewness mesh quality indicator.

\begin{tabular}{|c|c|c|c|c|c|}
\hline Unacceptable & Poor & Acceptable & Good & Very good & Excellent \\
\hline $0.98-1.00$ & $0.95-0.97$ & $0.80-0.94$ & $0.50-0.80$ & $0.25-0.550$ & $0-0.25$ \\
\hline
\end{tabular}

All studied mesh options are in line with the following quality parameters: Orthogonal Quality $>0.18$; Skewness $<0.80$.

Figure 3 shows the jet pump computational region cross-section, sampled into mesh elements.

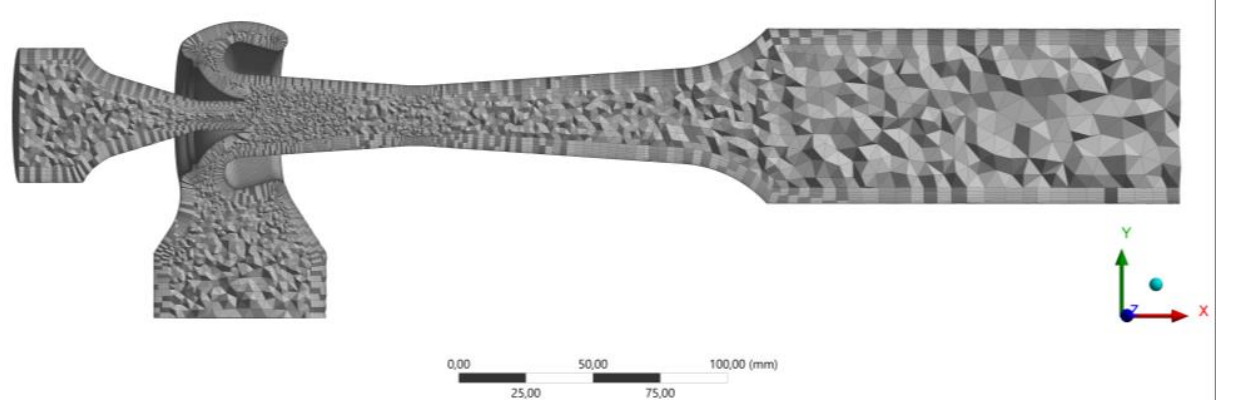

Fig. 3. Mesh with prismatic layers along solid walls (4 615189 elements).

Mesh independence calculations results are given in table 4 and figure 4.

Table 4. Influence of the number of grid elements on the calculation results.

\begin{tabular}{|c|c|c|c|c|c|c|}
\hline \multirow{2}{*}{$\begin{array}{l}\text { Number of } \\
\text { elements }\end{array}$} & \multicolumn{2}{|c|}{$G_{1 \exp }=3.589 \mathrm{~kg} / \mathrm{s}$} & \multicolumn{2}{|c|}{$G_{3 \exp }=3.609 \mathrm{~kg} / \mathrm{s}$} & \multicolumn{2}{|c|}{$G_{2 \exp }=7.189 \mathrm{~kg} / \mathrm{s}$} \\
\hline & $\mathbf{G}_{1 \text { calc }}, \mathrm{kg} / \mathrm{s}$ & $\delta, \%$ & $\begin{array}{c}\mathbf{G}_{3 \text { calc }}, \\
\mathbf{k g} / \mathbf{s}\end{array}$ & $\delta, \%$ & $\mathbf{G}_{2 \text { calc }}, \mathrm{kg} / \mathrm{s}$ & $\delta, \%$ \\
\hline 1711115 & 3.724 & 3.76 & 3.182 & -11.83 & 6.906 & -4.06 \\
\hline 2499489 & 3.727 & 3.84 & 3.203 & -11.25 & 6.930 & -3.73 \\
\hline 3546992 & 3.727 & 3.84 & 3.308 & -8.34 & 7.035 & -2.27 \\
\hline 4615189 & 3.730 & 3.92 & 3.421 & -5.21 & 7.151 & -0.66 \\
\hline 5502019 & 3.731 & 3.95 & 3.415 & -5.38 & 7.146 & -0.73 \\
\hline 6438480 & 3.731 & 3.95 & 3.407 & -5.60 & 7.138 & -0.84 \\
\hline
\end{tabular}




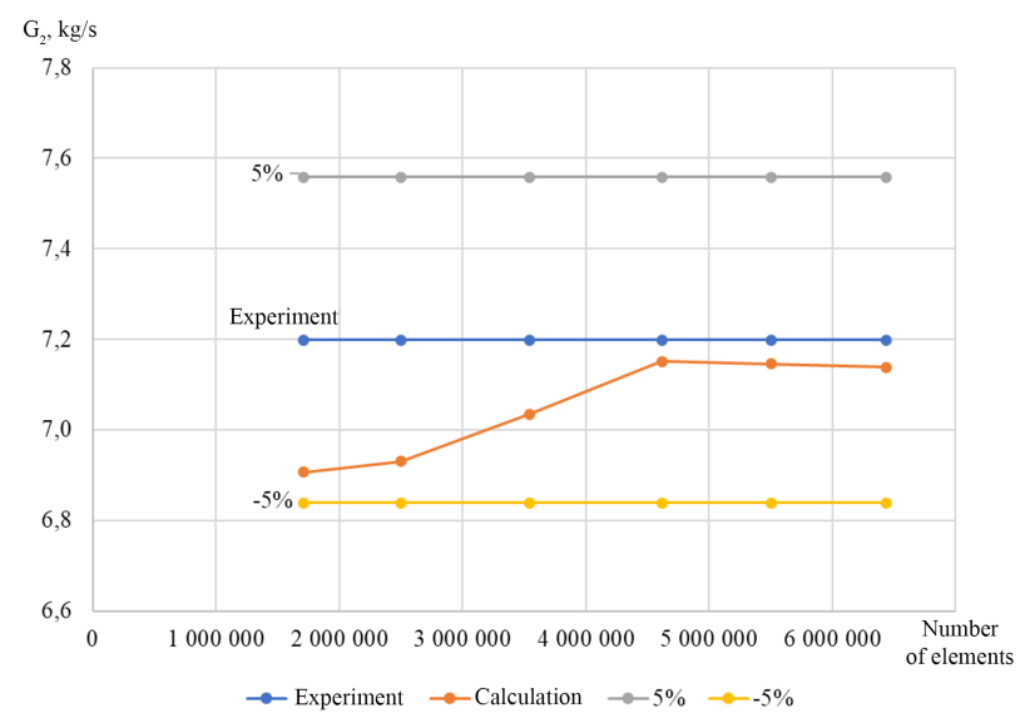

Fig. 4. Mass flow rate of JP discharge dependence on the number of grid elements.

As a result of conducted computations, the value of grid elements number, starting from which further increase in their number does not result in alteration of the pump quantitative parameters, comprised approximately 4.5 million.

\subsection{Comparison of numeric computation results in ANSYS and OpenFOAM}

In ANSYS the computations were carried out in CFX and Fluent modules [1]. In the course of computation in OpenFOAM, the Simplefoam equation solver [2] was used, which is a stationary solver for incompressible turbulent flow, implementing SIMPLE (Semi-Implicit Method for Pressure Linked Equations) algorithm. An important difference between this solver and the solver used in ANSYS CFX is the calculation method. ANSYS CFX uses the Coupled computation method [2], in which the process of numerical solving the momentum transfer equations and the pressure correction procedure are combined and performed simultaneously by solving joint system of discrete equations. This solution approach uses fully implicit discretization of equations at any given time step. Simplefoam solver uses Segregated computation method [3], in which the process of numerical solving the momentum transfer equations and the pressure correction procedure are performed successively. An important difference between Simplefoam and the solver implemented in the computation in ANSYS CFX is the fact that in Simplefoam, the Rhie-Chow interpolation is not performed explicitly [4], as opposed to ANSYS CFX. ANSYS Fluent module has an opportunity to use both SIMPLE algorithm and PISO algorithm.

The numerical computation of the jet pump characteristics was carried out at different pressures. Absolute pressures values, at which the calculations were carried out, are given in table 5.

Table 5. Boundary conditions for design points.

\begin{tabular}{|c|c|c|c|}
\hline № & $\boldsymbol{P}_{\boldsymbol{1}}(\mathbf{P a})$ & $\boldsymbol{P}_{\mathbf{3}} \mathbf{( P a )}$ & $\boldsymbol{P}_{\text {static }} \mathbf{( P a )}$ \\
\hline 1 & 888882 & 80924 & 242067 \\
\hline 2 & 790863 & 83289 & 222506 \\
\hline
\end{tabular}




\begin{tabular}{|l|l|l|l|}
\hline 3 & 692827 & 85153 & 204901 \\
\hline 4 & 594883 & 86641 & 191208 \\
\hline 5 & 496853 & 89383 & 171647 \\
\hline 6 & 398813 & 90971 & 154042 \\
\hline 7 & 300729 & 92978 & 134481 \\
\hline
\end{tabular}

Tables $6,7,8$ contain the working fluid mass flow values $G_{1}$, obtained in the experiment, computations in ANSYS CFX, OpenFOAM, ANSYS Fluent packages, as well as an error related to experimental data.

Table 6. Results of calculations in ANSYS CFX.

\begin{tabular}{cccccccccc}
\hline \multirow{2}{*}{ o } & $\begin{array}{c}G_{1 \text { CFX }} \\
(\mathrm{kg} / \mathrm{s})\end{array}$ & $\begin{array}{c}G_{2} \text { CFX } \\
(\mathrm{kg} / \mathrm{s})\end{array}$ & $\begin{array}{c}G_{3 \text { CFX }} \\
(\mathrm{kg} / \mathrm{s})\end{array}$ & $\begin{array}{c}G_{1 \exp } \\
(\mathrm{kg} / \mathrm{s})\end{array}$ & $\begin{array}{c}G_{2 \exp } \\
(\mathrm{kg} / \mathrm{s})\end{array}$ & $\begin{array}{c}G_{3 \exp } \\
(\mathrm{kg} / \mathrm{s})\end{array}$ & $\begin{array}{c}\delta_{1} \\
(\%)\end{array}$ & $\begin{array}{c}\delta_{2} \\
(\%)\end{array}$ & $\begin{array}{c}\delta_{3} \\
(\%)\end{array}$ \\
\hline 1 & 3,779 & 6,885 & 3,106 & 3,589 & 7,198 & 3,609 & 5,29 & 4,35 & 13,94 \\
2 & 3,535 & 6,429 & 2,893 & 3.35 & 6,78 & 3,43 & 5,52 & 5,18 & 15,66 \\
3 & 3,275 & 5,956 & 2,681 & 3,091 & 6,281 & 3,19 & 5,95 & 5,17 & 15,96 \\
4 & 2,992 & 5,363 & 2,371 & 2,911 & 5,832 & 2,921 & 2,78 & 8,04 & 18,83 \\
5 & 2,679 & 4,832 & 2,153 & 2,592 & 4,835 & 2,243 & 3,36 & 0,06 & 4,01 \\
6 & 2,326 & 4,198 & 1,872 & 2,223 & 4,187 & 1,964 & 4,63 & 0,26 & 4,68 \\
7 & 1,91 & 3,506 & 1,595 & 1,685 & 3,141 & 1,456 & 13,35 & 11,62 & 9,55 \\
\hline
\end{tabular}

Table 7. Results of calculations in OpenFOAM.

\begin{tabular}{cccccccccc}
\hline № & $\begin{array}{c}G_{1} \text { CFX } \\
(\mathrm{kg} / \mathrm{s})\end{array}$ & $\begin{array}{c}G_{2} \text { CFX } \\
(\mathrm{kg} / \mathrm{s})\end{array}$ & $\begin{array}{c}G_{3} \text { CFX } \\
(\mathrm{kg} / \mathrm{s})\end{array}$ & $\begin{array}{c}G_{1 \exp } \\
(\mathrm{kg} / \mathrm{s})\end{array}$ & $\begin{array}{c}G_{2} \exp \\
(\mathrm{kg} / \mathrm{s})\end{array}$ & $\begin{array}{c}G_{3} \exp \\
(\mathrm{kg} / \mathrm{s})\end{array}$ & $\begin{array}{c}\delta_{1} \\
(\%)\end{array}$ & $\begin{array}{c}\delta_{2} \\
(\%)\end{array}$ & $\begin{array}{c}\delta_{3} \\
(\%)\end{array}$ \\
\hline 1 & 3,560 & 6,894 & 3,334 & 3,589 & 7,198 & 3,609 & 0,80 & 4,22 & 7,63 \\
2 & 3,346 & 6,963 & 3,618 & 3,35 & 6,78 & 3,43 & 0,13 & 2,70 & 5,47 \\
3 & 3,094 & 6,264 & 3,170 & 3,091 & 6,281 & 3,19 & 0,10 & 0,28 & 0,64 \\
4 & 2,821 & 5,369 & 2,548 & 2,911 & 5,832 & 2,921 & 3,11 & 7,95 & 12,77 \\
5 & 2,531 & 5,081 & 2,550 & 2,592 & 4,835 & 2,243 & 2,36 & 5,08 & 13,68 \\
6 & 2,198 & 4,387 & 2,189 & 2,223 & 4,187 & 1,964 & 1,11 & 4,78 & 11,44 \\
7 & 1,802 & 3,489 & 1,687 & 1,685 & 3,141 & 1,456 & 6,94 & 11,06 & 15,84 \\
\hline
\end{tabular}

Table 8. Results of calculations in ANSYS Fluent.

\begin{tabular}{cccccccccc}
\hline № & $\begin{array}{c}G_{1} \text { CFX } \\
(\mathrm{kg} / \mathrm{s})\end{array}$ & $\begin{array}{c}G_{2} \text { CFX } \\
(\mathrm{kg} / \mathrm{s})\end{array}$ & $\begin{array}{c}G_{3} \text { CFX } \\
(\mathrm{kg} / \mathrm{s})\end{array}$ & $\begin{array}{c}G_{1 \exp } \\
(\mathrm{kg} / \mathrm{s})\end{array}$ & $\begin{array}{c}G_{2} \exp \\
(\mathrm{kg} / \mathrm{s})\end{array}$ & $\begin{array}{c}G_{3} \exp \\
(\mathrm{kg} / \mathrm{s})\end{array}$ & $\begin{array}{c}\delta_{1} \\
(\%)\end{array}$ & $\begin{array}{c}\delta_{2} \\
(\%)\end{array}$ & $\begin{array}{c}\delta_{3} \\
(\%)\end{array}$ \\
\hline 1 & 3,727 & 6,929 & 3,203 & 3,589 & 7,198 & 3,609 & $-3,85$ & 3,74 & 11,25 \\
2 & 3,487 & 6,531 & 3,044 & 3,35 & 6,78 & 3,43 & $-4,09$ & 3,67 & 11,25 \\
3 & 3,23 & 6,057 & 2,827 & 3,091 & 6,281 & 3,19 & $-4,50$ & 3,57 & 11,38 \\
4 & 2,949 & 5,424 & 2,476 & 2,911 & 5,832 & 2,921 & $-1,31$ & 7,00 & 15,23 \\
5 & 2,64 & 4,912 & 2,273 & 2,592 & 4,835 & 2,243 & $-1,85$ & $-1,59$ & $-1,34$ \\
6 & 2,291 & 4,24 & 1,949 & 2,223 & 4,187 & 1,964 & $-3,06$ & $-1,27$ & 0,76 \\
7 & 1,88 & 3,531 & 1,651 & 1,685 & 3,141 & 1,456 & $-11,57$ & $-12,42$ & $-13,39$ \\
\hline
\end{tabular}

Figure 5 shows the dependence of mass flow rate at discharge on the working flow pressure per numerical modeling results. Figure 6 and figure 7 present the velocity distributions in the flow part of the jet pump, obtained as a result of computation in ANSYS CFX and OpenFOAM. 


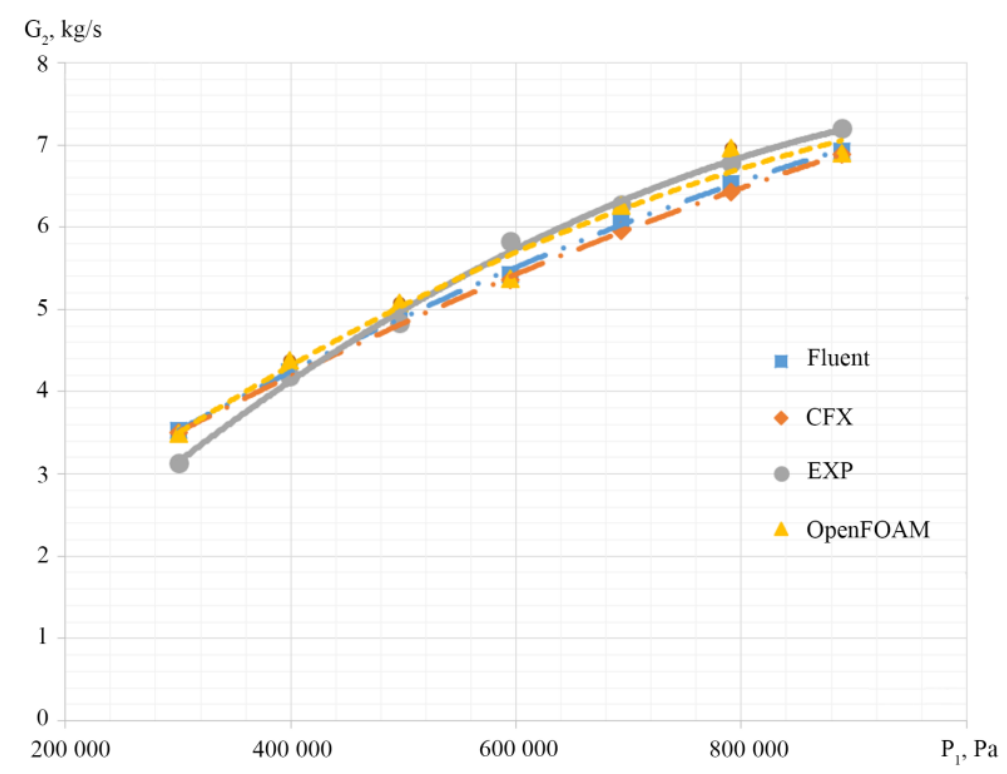

Fig. 5. Dependence of mass flow rate at discharge on the working flow pressure

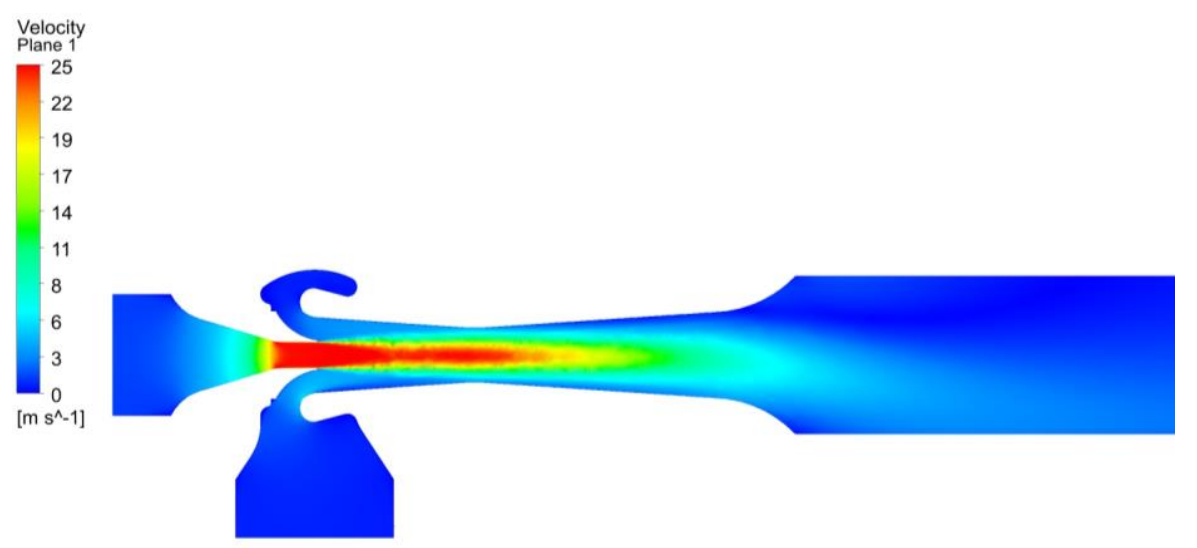

Fig. 6. Velocity distribution in the jet pump flow part section, when calculated in ANSYS CFX

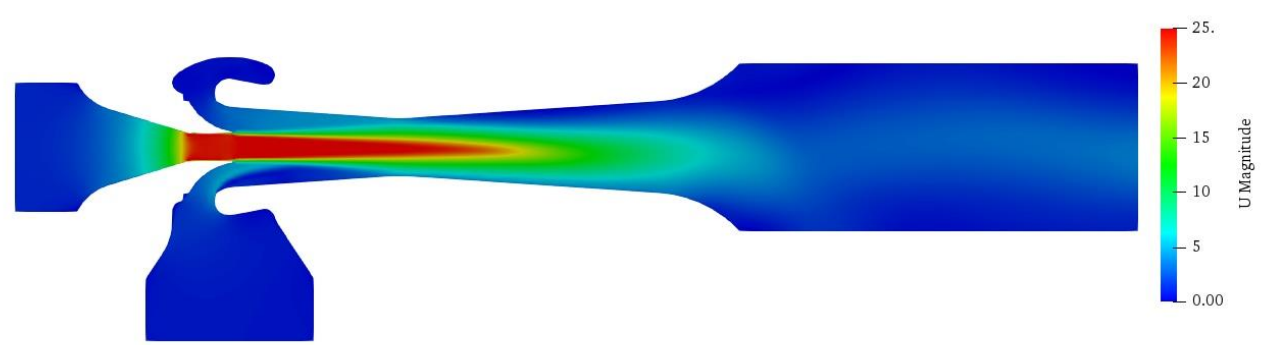

Fig. 7. Velocity distribution in the jet pump flow part section, when calculated in OpenFOAM 


\section{Conclusion}

From the results of the study, it follows that the highest average value of mass flow rate deviations at jet pump discharge is given by OpenFOAM, comprising $5.15 \%$. Minimum average value of mass flow deviations is given by ANSYS Fluent, comprising $4.75 \%$, but at the same time, ANSYS Fluent gives maximum absolute deviation among all values, comprising $12.42 \%$. Average mass flow deviation at discharge for ANSYS CFX is $4.96 \%$.

\section{References}

1. P. Welahettige and Vaagsaether K. Comparison of OpenFOAM and ANSYS Fluent Proceedings of The 9th EUROSIM Congress on Modelling and Simulation, EUROSIM 2016, The 57th SIMS Conference on Simulation and Modelling SIMS 2016 vol 142 (Linköping University Electronic Press) pp 1005-12, 2018

2. N. Minocha and Joshi J. B. 3D CFD simulation of turbulent flow distribution and pressure drop in a dividing manifold system using openfoam International Journal of Heat and Mass Transfer 151 119420, 2020

3. G. Hauke, Landaberea A., Garmendia I. and Canales J. A segregated method for compressible flow computation Part I: isothermal compressible flows International Journal for Numerical Methods in Fluids 47 271-323, 2005

4. S. Zhang, Zhao X. and Bayyuk S. Generalized formulations for the rhie-chow interpolation Journal of Computational Physics 258 880-914, 2014 